\title{
RF MEMS Phase Shifters and Their Application in Phase Array Antennas
}

\author{
Maximilian C. Scardelletti, George E. Ponchak, Afroz J. Zaman, and Richard Q. Lee
}

\begin{abstract}
Electronically scanned arrays are required for space based radars that are capable of tracking multiple robots, rovers, or other assets simultaneously and for beam-hopping communication systems between the various assets. Traditionally, these phased array antennas used GaAs MMIC phase shifters, power amplifiers, and low noise amplifiers to amplify and steer the beam, but the development of RF MEMS switches over the past ten years has enabled system designers to consider replacing the GaAs MMIC phase shifters with RF MEMS phase shifters. In this paper, the implication of replacing the relatively high loss GaAs MMICs with low loss MEMS phase shifters is investigated.
\end{abstract}

Index Terms - Phase Arrays, Antennas, MEMS, Phase Shifters

\section{INTRODUCTION}

Communication links between multiple rovers, sensors, satellites, human occupied modules and spacecraft are required by many NASA missions. In addition to communication links, radar systems are required to map the planets and detect and track space objects to enable spacecraft to maneuver away from possible collisions. Currently these tasks are commonly performed with omni directional antennas and steerable parabolic dishes. However as the new space exploration initiative with prolonged human presence on the Moon and Mars, phased arrays will take a more active role in securing the future of these communication systems.

Electronically Scanned Arrays (ESAs) or phased array antennas use electronic, mechanical, or material switches to alter the phase of individual radiating elements across an antenna, and in so doing, enable the radiated beam to steer [1]. Communication and radar systems incorporating phased arrays will enable greater efficiency, higher data rates and increase access between greater numbers of links.

In the past ten years, RF MicroElectroMechanical (MEMs) switches and phase shifters have been developed that exhibit excellent characteristics, including low insertion loss and low DC power consumption. In this paper, we review the performance of RF MEMS phase shifters and compare them to Monolithic Microwave Integrated Circuit (MMIC) phase

M. C. Scardelletti, G. E. Ponchak, A. J. Afroz, and R. Q. Lee are with NASA Glenn Research Center, Brook Park, OH 44135. email: Maximilian.C.Scardelletti@nasa.gov.

This paper was funded by the NASA CICT Program Office, NASA Glenn Research Center, Brook Park, OH, 44135. shifters, which are mostly based on GaAs transistor switches. Finally, we present the impact on the communication system if an RF MEMS based ESA were to replace a MMIC based array.

\section{ELECTRONICALly SCANNED ARRAYS}

Electronically scanned array antennas may be classified as either active ESAs or passive ESAs. In active ESA's, the RF power generation by the power amplifiers (PAs) and the amplification of the received power by the low noise amplifiers (LNAs) is distributed among the antenna elements. This reduces the RF power loss in the distribution network and distributes the generated heat. Passive arrays utilize the opposite approach to RF power generation; passive ESAs use a single PA to generate all of the RF power, and this RF power is distributed among the antenna elements by the beam forming network. The advantage of passive arrays is a decrease in the number of components in the array and a possible cost savings. A hybrid ESA uses a smaller passive ESA as a sub-array of an active ESA. With this approach, lower cost and system complexity of the passive ESA is traded-off against the better system performance of the active ESA. In this paper, the impact of replacing a high loss phase shifter with a low loss phase shifter is investigated with the goal of determining if RF MEMS phase shifters affects the system choice.

\section{RF MEMS SWITCHES}

A rotating type RF MEMS switch and a metal contact cantilever beam switch [2,3] for microwave frequency circuits were first demonstrated in 1991. At the present time, all MEMS switches embedded within microwave transmission lines operate as reflective switches, or devices that create a loading condition that causes the electrical signal to be reflected back in the direction from which it came. Furthermore, only metal cantilever type switches are being reported. In general, these switches consist of a single or double supported metal cantilever suspended over a microwave transmission line and bias circuit. In its up state, the cantilever is several microns above the circuit, but if an electromagnetic force is applied between the cantilever and bias circuit, the cantilever is pulled down and interacts with the circuit. Because the electromagnetic force is always attractive, the 10 to $50 \mathrm{~V}$ bias voltage may be applied to the transmission line or the cantilever and it may be either 
positive or negative voltage, but this also means that the return of the switch to the up state relies on the restoring force of the metal.

There are two types of MEMS switches: capacitive and metal-to-metal contact switches. Capacitive switches, as shown in Fig. 1, employ a thin insulator between the transmission line and the cantilever to prevent the two metal structures from touching. Thus, when the switch is in the up state, a very small capacitance due to the 3 to 5 micron of air gap has very little effect on the electrical signal; However, when the cantilever is in the down state, a very large capacitance due to the thin insulator results in an effective short circuit at high frequencies, which reflects the electrical signal. Because capacitive switches rely on a change in capacitance, they are ineffective at low frequencies, but virtually no direct current flows in the bias circuit of capacitive switches. Metal-to-metal contact switches are often fabricated as series switches that has a gap in the transmission line that prevents signal propagation when the switch is up, and when the switch is pulled down, a metal bar completes the circuit. Because the metal contacts are resistive, the insertion loss of these switches increases with frequency. Thus, these circuits are effective from DC to microwave frequencies, but they are not effective at millimetre-wave frequencies.

RF MEMS switches are mechanical devices that do not rely on the characteristics of the substrate. Thus, they may be fabricated on any material that is compatible with standard IC processing steps. Silicon substrates are often used because silicon processing is well understood; wafers are available in large diameters, which lowers fabrication cost; and there are many MEMS sensors and actuators already fabricated on Si. However, microwave circuits are typically fabricated on GaAs or InP because these materials have high electron mobilities, which permits transistors to operate through $100 \mathrm{GHz}$ and higher. In addition, quartz and alumina are often used for hybrid circuits because they have low loss. RF MEMS switches and circuits have been fabricated on each of these materials.

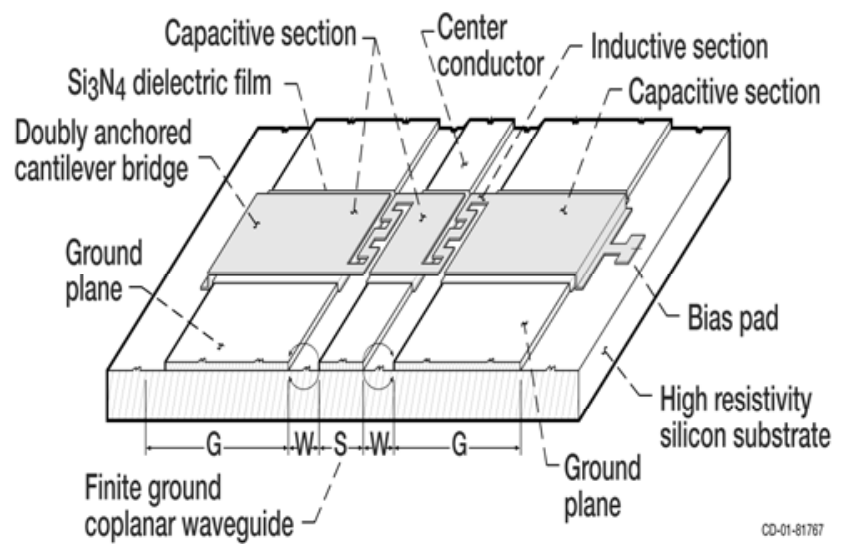

Figure 1: RF MEMS capacitive switch.

\section{Phase Shifters}

There are three types of MMIC phase shifters. The first uses switches to direct electrical signals through either a short or long length of transmission line; these are called switched line phase shifters. The second switches the electrical signal between two circuits that have opposite phase characteristics; typically the two circuits are a high pass and a low pass filter. The third type uses variable capacitors to alter the propagation constant of the transmission line [4].

GaAs MMIC phase shifters have been in development since the early 1980's [5-7], and they are now commercially available as cataloged parts [8-10]. The first RF MEMS phase shifters were not reported until 1999 [11], but since then, many circuits covering the frequency range from 8 to $94 \mathrm{GHz}$ have been reported [12-17]. Both GaAs MMIC phase shifters and MEMS phase shifters have advantages and disadvantages.

Because MEMS switches are dependent on the movement of a mechanical structure, they are relatively slow compared to electronic devices. An electrostatically activated MEMS switch, such as described above, has a switching speed of 10$100 \mu \mathrm{sec}$, and thermally activated MEMS switches have a switching speed of 1-10 msec. This switching speed is slow in comparison to PIN diode and MESFET switching speeds in the nsec range. However, the switching speed is not critical except in very high data rate, beam hopping communication systems.

Contrary to popular belief, MEMS switches and circuits based on them are not smaller than electronic circuits. Note that the MEMS cantilever is over 100 micron long by 20 to 200 micron wide, but a transistor is 0.15 to 1 micron by 20 micron. Thus, MEMS switches will not be used in integrated circuits such as computer chips, but RF integrated circuit size is dependent on the passive circuits, not the active devices. Therefore, the difference in circuit size between MMIC and MEMS phase shifters is small; $\mathrm{X}$ and W-Band phase shifters of each type differ in size by less than a factor of two, as shown in Table 1. Once MEMS technology matures to a commercially viable product, reduction in size will occur.

Table 1: Size of MMIC and MEMS phase shifters.

\begin{tabular}{|l|l|l|l|l|}
\hline $\begin{array}{l}\text { Freq } \\
\text { Band }\end{array}$ & $\begin{array}{l}\text { MMIC } \\
\text { size }\left(\mathrm{cm}^{2}\right)\end{array}$ & $\begin{array}{l}\text { MMIC } \\
\text { size }\left(\lambda^{2}\right)\end{array}$ & $\begin{array}{l}\text { MEMS } \\
\text { size }\left(\mathrm{cm}^{2}\right)\end{array}$ & $\begin{array}{l}\text { MEMS } \\
\text { size }\left(\lambda^{2}\right)\end{array}$ \\
\hline $\mathrm{X}$ & 0.090 & 0.014 & 0.069 & 0.007 \\
\hline $\mathrm{Ka}$ & 0.012 & 0.012 & 0.091 & 0.091 \\
\hline $\mathrm{W}$ & 0.045 & 0.405 & 0.097 & 0.654 \\
\hline
\end{tabular}

Prime power consumption favors MEMS switches. Capacitive MEMS switches consume negligible DC power only during the switching time. Metal contact MEMS switches also use a separate bias pad that is the equivalent of a capacitive switch. Thus, metal contact switches also consume negligible DC power. Although MEMS switches with a pull down voltage less than $10 \mathrm{~V}$ have been demonstrated, bias voltages of 20 to $40 \mathrm{~V}$ have greater mechanical stability. Moreover, to avoid charging of the insulator between the cantilever and lower metal contact, the bias voltage is varied between positive and negative pulses. Thus, MEMS circuits consume zero DC power, but require complicated bias control 
circuits. GaAs MESFET and PHEMT MMIC phase shifters consume 50 and $8 \mathrm{~mW}$, respectively, but standard bias voltages are used. For small arrays, the difference in DC power consumption is negligible, but for large arrays of 1000 elements, MMIC phase shifters would consume $50 \mathrm{~W}$.

The most significant advantage of MEMS phase shifters is the low insertion loss of MEMS switches. Fig. 2 summarizes all of the phase shifters of each type. At $8 \mathrm{GHz}$, a four-bit phase shifter would have $2.5 \mathrm{~dB}$ and $6.4 \mathrm{~dB}$ insertion loss for MEMS and MMIC phase shifters, respectively. At $30 \mathrm{GHz}$, the same phase shifter would have 3.24 and $8.16 \mathrm{~dB}$ insertion loss for MEMS and MMIC phase shifters, respectively, if the average insertion loss is used. If the best reported insertion loss for each type is compared, the MEMS phase shifters still have $3 \mathrm{~dB}$ lower insertion loss at both frequency bands. Above Ka-band, MEMS phase shifters have significantly lower insertion loss. Thus, if nothing else changes in the antenna system, a MEMS based array would have $5.5 \mathrm{~dB}$ higher EIRP than an electronic circuit based phase shifter.

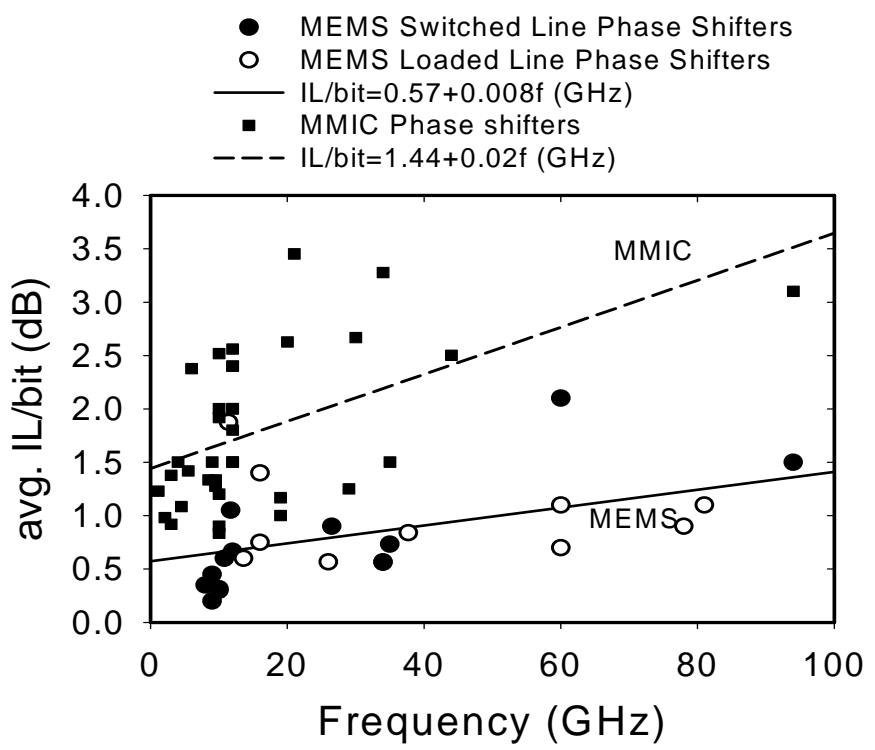

Figure 2: Average insertion loss per bit versus frequency for MEMS and MMIC phase shifters.

Because there are no cataloged MEMS phase shifters, cost cannot be compared. Moreover, MEMS foundries are not readily available. Since GaAs MMIC phase shifters are commercially available, MMICs must be considered a more mature technology. Besides availability, GaAs MMICs have a long history of reliability, but MEMS switch reliability is still being investigated through industry internal research and development and government funding. Thus, while MEMS switches have shown 100 billion cycles in controlled laboratory tests, full, space or MILSPEC qualification of MEMS switches has not been reported.

\section{EO-1 ANTENNA COMPARISON}

NASA has incorporated phased array systems into three missions: Lunar Prospector, Earth Observing 1 (EO-1), and Messenger. The New Millennium Program's Earth Observing-
1 (EO-1) mission is demonstrating an on-orbit, high data rate, low mass X-Band Phased Array Antenna (XPAA) for downlinking imaged data from the EO-1 solid state recorder. The XPAA offers significant benefits over current mechanically pointed parabolic antennas, including the elimination of deployable structures, moving parts, and the torque disturbances that moving antennas impart to the spacecraft.

The active ESA of EO-1 is composed of a flat grid of 64 radiating elements whose transmitted signals are combined spatially to produce the desired antenna directivity. Each dielectrically loaded, circular waveguide antenna is fed by a dual power amplifier operating $90^{\circ}$ out of phase to create lefthand circular polarization. The transmit/receive module is comprised of a 4-bit phase shifter, a driver amplifier, a dual power amplifier, and an application specific integrated circuit controller.

The 4-bit high-/low-pass phase shifter used in the EO-1 transmit module has a frequency band of $7.0-9.0 \mathrm{GHz}$, an insertion loss (IL) of $5.0+/-0.4 \mathrm{~dB}$, and it is fabricated using Agilent's $0.25 \mu \mathrm{m}$ PHEMT (PH9A) fabrication process. The antenna has an EIRP of approximately 160 watts (22dBw), and transmits data at $52.5 \mathrm{Mbps}$ per channel. If the PHEMT, 4-bit phase shifter is replaced by a MEMS, 4-bit phase shifter with $3 \mathrm{~dB}$ lower insertion loss and the transmitter power is kept constant, the system can support twice the data rate with a receive antenna diameter of half of the EO-1 receive antenna. Table 2 summarizes the EO- 1 link budget with the significant changes due to the lower insertion loss of the MEMS phase shifter in bold type. Alternatively, the system link margin and data rate can be maintained, and the number of elements may be reduced from 64 to 32 .

Table 2: EO-1 active phased array comparison.

\begin{tabular}{|l|l|l|}
\hline & EO-1 XPAA & MEMS Array \\
\hline Range (GEO) & $2574.3 \mathrm{~km}$ & $2574.3 \mathrm{~km}$ \\
\hline Down Link Frequency & $8.2 \mathrm{GHz}$ & $8.2 \mathrm{GHz}$ \\
\hline Transmitter Power & $5.05 \mathrm{dBW}$ & $5.05 \mathrm{dBW}$ \\
\hline BFN and feed Loss & $4.51 \mathrm{~dB}$ & $\mathbf{1 . 5 1} \mathbf{~ d B}$ \\
\hline Pointing Loss & $0.25 \mathrm{~dB}$ & $0.25 \mathrm{~dB}$ \\
\hline Transm Antenna Gain & $21.71 \mathrm{dBi}$ & $21.71 \mathrm{dBi}$ \\
\hline Transmitter EIRP & $22 \mathrm{dBW}$ & $\mathbf{2 5 ~ d B W}$ \\
\hline Free Space Path Loss & $178.93 \mathrm{~dB}$ & $178.93 \mathrm{~dB}$ \\
\hline Atmosphere Loss & $0.80 \mathrm{~dB}$ & $0.80 \mathrm{~dB}$ \\
\hline Received EIRP & $-157.73 \mathrm{dBW}$ & $\mathbf{- 1 5 4 . 7 3 ~ d B W}$ \\
\hline Receive Antenna Gain & $44.3 \mathrm{~dB}, 2.7 \mathrm{~m}$ & $\mathbf{4 1 . 3 ~ d B , ~ 1 . 3 m}$ \\
\hline Received Signal Power & $-113.43 \mathrm{dBW}$ & $\mathbf{- 1 1 3 . 4 3 ~ d B W}$ \\
\hline Ground System G/T & $22 \mathrm{~dB} / \mathrm{K}$ & $22 \mathrm{~dB} / \mathrm{K}$ \\
\hline System Effective Temp & $22.3 \mathrm{~dB}-\mathrm{K}$ & $\mathbf{1 9 . 3 ~ d B - K}$ \\
\hline NSD No=kT dBW/Hz & -206.3 & $\mathbf{- 2 0 9 . 3}$ \\
\hline C/No at Receiver Input & $92.87 \mathrm{~dB}-\mathrm{Hz}$ & $\mathbf{9 5 . 8 7} \mathbf{~ d B}-\mathbf{H z}$ \\
\hline Data Rate & $52.5 \mathrm{Mbps}$ & $\mathbf{1 0 5} \mathbf{M b p s}$ \\
\hline Received Eb/No & $15.67 \mathrm{~dB}$ & $\mathbf{2 4 . 9 5 ~ d B}$ \\
\hline Mod. \& coding Loss & $6.6 \mathrm{~dB}$ & $6.6 \mathrm{~dB}$ \\
\hline Required Eb/No & $6.38 \mathrm{~dB}$ & $6.38 \mathrm{~dB}$ \\
\hline Link Margin & $2.686 \mathrm{~dB}$ & $2.676 \mathrm{~dB}$ \\
\hline
\end{tabular}




\section{ACTS ANTENNA COMPARISON}

NASA Glenn Research Center developed the Advanced Communication Technology Satellite (ACTS) to prove the use of Ka-Band communication systems with a hopping beam antenna [18,19]. ACTS used a $20 \mathrm{GHz}$ downlink and a 30 $\mathrm{GHz}$ uplink, with the antenna for each link comprised of a reflector fed by a cluster of feed horns. By switching between feed horns, the shape and direction of the radiation pattern can be varied. Moreover, the beam may be hopped between Earth locations by switching between feed horns. A modern version of ACTS may use a small phase array to feed the reflector antenna. In this way, the cluster of feed horns and the switch matrix that drives them would be eliminated. Table 3 compares a link between ACTS and a small Earth terminal with a phase array feed of the ACTS reflector antenna. For this link analysis, the transmitter power and the size of the phase array are kept constant; A 14-element array is assumed. Furthermore, based on the state of the art in MMIC and MEMS phase shifters at $20 \mathrm{GHz}$, the MEMS phase shifter has $4 \mathrm{~dB}$ lower insertion loss than the MMIC phase shifter. The significant conclusions of the link analysis are that the data rate to the small terminals may be doubled to $7 \mathrm{Mbps}$ while the ground station antenna size may be reduced to a $17 \mathrm{~cm}$ aperture.

Table 3: ACTS and MEMS phase array comparison.

\begin{tabular}{|l|l|l|}
\hline & MMIC Array & MEMS Array \\
\hline Range (GEO) & $37,880 \mathrm{~km}$ & $37,880 \mathrm{~km}$ \\
\hline Down Link Frequency & $19.47 \mathrm{GHz}$ & $19.47 \mathrm{GHz}$ \\
\hline Transmitter Power & $15.9 \mathrm{dBW}$ & $15.9 \mathrm{dBW}$ \\
\hline BFN and feed Loss & $6.5 \mathrm{~dB}$ & $\mathbf{2 . 5} \mathbf{~ d B}$ \\
\hline Pointing Loss & $0.85 \mathrm{~dB}$ & $0.85 \mathrm{~dB}$ \\
\hline Transm Antenna Gain & $54.2 \mathrm{dBi}$ & $54.2 \mathrm{dBi}$ \\
\hline Transmitter EIRP & $62.75 \mathrm{dBW}$ & $62.75 \mathrm{dBW}$ \\
\hline Free Space Path Loss & $209.797 \mathrm{~dB}$ & $209.797 \mathrm{~dB}$ \\
\hline Atmosphere Loss & $0.9 \mathrm{~dB}$ & $0.9 \mathrm{~dB}$ \\
\hline Received EIRP dBW & -149.647 & $\mathbf{- 1 4 5 . 6 4 7}$ \\
\hline Receive Antenna Gain & $38.5 \mathrm{~dB}, 0.35 \mathrm{~m}$ & $\mathbf{3 4 . 5} \mathbf{~ d B}, \mathbf{0 . 1 7 m}$ \\
\hline Received Signal Power & $-111.147 \mathrm{dBW}$ & $-111.147 \mathrm{dBW}$ \\
\hline Ground System G/T & $22 \mathrm{~dB} / \mathrm{K}$ & $22 \mathrm{~dB} / \mathrm{K}$ \\
\hline System Effective Temp & $16.5 \mathrm{~dB}-\mathrm{K}$ & $\mathbf{1 2 . 5} \mathbf{~ d B}-\mathbf{K}$ \\
\hline NSD No=kT dBW/Hz & -212.1 & $\mathbf{- 2 1 6 . 1}$ \\
\hline C/No at Receiver Input & $100.95 \mathrm{~dB}-\mathrm{Hz}$ & $\mathbf{1 0 4 . 9 5 ~ d B - H z}$ \\
\hline Data Rate & $3.088 \mathrm{Mbps}$ & $\mathbf{7 . 0 8 8 ~ \mathbf { ~ M b s }}$ \\
\hline Received Eb/No & $36.056 \mathrm{~dB}$ & $36.447 \mathrm{~dB}$ \\
\hline Mod. \& coding Loss & $6.6 \mathrm{~dB}$ & $6.6 \mathrm{~dB}$ \\
\hline Required Eb/No & $7.5 \mathrm{~dB}$ & $7.5 \mathrm{~dB}$ \\
\hline Link Margin & $21.96 \mathrm{~dB}$ & $21.35 \mathrm{~dB}$ \\
\hline
\end{tabular}

\section{CONCLUSION}

RF MEMS phase shifters have been demonstrated with significant advantages over GaAs MMIC phase shifters, including lower insertion loss and no DC power consumption. These advantages led to significant improvements in phase array antennas. Link analysis of two NASA systems show that the data rate may be doubled while one of the two antennas may be halved. However, MEMS phased arrays have not been demonstrated yet, so these benefits have not been proven. Furthermore, MEMS phase shifters have not been space qualified, and there are no commercial MEMS phase shifters on the market. Thus, further development is required, including the space qualification of MEMS switches, demonstration of MEMS bias circuits in a large array, and qualification of a MEMS array.

\section{REFERENCES}

[1] R. C. Hansen, Phased Array Antennas, John Wiley \& Sons Inc., New York, New York, 1998.

[2] L. E. Larson, R. H. Hackett, and R. F. Lohr, "Microactuators for GaAsbased microwave integrated circuits," Int. Conf. Solid-State Sensors and Actuators Dig. (TRANSDUCERS '91), June 24-27, 1991, pp. 743 - 746.

[3] L. E. Larson, R. H. Hackett, M. A. Melendes, and R. F. Lohr, "Micromachined microwave actuator (MIMAC) technology-a new tuning approach for microwave integrated circuits," IEEE Int. Microwave and Millimeter-Wave Monolithic Circuits Symp. Dig., June 10-11, 1991, pp. 27 - 30.

[4] S. K. Koul and B. Bhat, Microwave and Millimeter Wave Phase Shifters: Vol. II Semiconductor and Delay Line Phase Shifters, Artech House, Boston, MA, 1991.

[5] S. Ya, C. Jiyi, C. Tangsheng, C. Xiaojian, and L. Jinting, "A compact Lband four-bit MMIC phase shifter," Microwave and Millimeter-Wave Technology Proc. (ICMMT), 1998, pp. 242-244.

[6] M. Rhodes, "Monolithic phase shifter for S-band inter-satellite data relay antenna," IEE Colloquium on Recent Advances in Microwave SubSystems for Space and Satellite Applications, March 18, 1993, pp. 1/1$1 / 6$.

[7] A. A. Lane, "GaAs MMIC phase shifters for phased arrays," IEE Colloquium on Solid State Components on Radar, Feb. 12, 1988, pp. 3/1-3/5.

[8] MaCom S-Band Phase Shifter \#MAPCGM0003

[9] Northrop Grumman 3-5.5 GHz Phase Shifter \#PHS2584

[10] MaCom 3.5-6 GHz Phase Shifter \#MAPCGM0002

[11] A. Malczewski, S. Eshelman, B. Pillans, J. Ehmke, and C. L. Goldsmith, "X-Band RF MEMS phase shifters for phased array applications," IEEE Microwave and Guided Wave Lett., Vol. 9. No. 12, pp. 517-519, Dec. 1999.

[12] J. J. Lee, C. Quan, R. Allison, A. Reinehr, B. Pierce, R. Y. Loo, and J. Schaffner, "Array antennas using low loss MEMS phase shifters," 2002 IEEE Antennas and Propagation Society Int. Symp. Dig., Vol. 2 , June 16-21 2002, pp. $14-17$.

[13] G. - L. Tan, R. E. Mihailovich, J. B. Hacker, J. F. DeNatale, and G. M. Rebeiz, "Low-loss 2- and 4- bit TTD MEMS phase shifters based on SP4T switches," IEEE Trans. Microwave Theory and Tech., Vol. 51, No. 1, pp. 297-304, Jan. 2003.

[14] M. C. Scardelletti, G. E. Ponchak, and N. C. Varaljay, "Ka-Band, MEMS switched line phase shifters implemented in finite ground coplanar waveguide," 32nd European Microwave Conference Dig., Milan, Italy, Sept. 23-27, 2002, pp. 797-800.

[15] B. Pillans, S. Eshelman, A. Malczewski, J. Ehmke, and C. Goldsmith, "Ka-Band RF MEMS phase shifters," IEEE Microwave and Guided Wave Lett., Vol. 9, No. 12, pp. 520-522, Dec. 1999.

[16] J. B. Hacker, R. E. Mihailovich, M. Kim, and J. F. DeNatale, “A KaBand 3-bit RF MEMS true-time-delay network," IEEE Trans. Microwave Theory Tech., Vol. 51, No. 1, Jan. 2003, pp. 305-308.

[17] H.-T. Kim, J.-H. Park, J. Yim, Y.-K. Kim, and Y. Kwon, "A compact Vband 2-bit reflection-type MEMS phase shifter," IEEE Microwave and Wireless Comp. Lett., Vol. 12, No. 9, Sept. 2002, pp. 324-326.

[18] F. A. Regier, "The ACTS multibeam antenna," IEEE Trans. Microwave Theory and Tech., Vol. 40, No. 6, pp. 1159-1164, June 1992.

[19] P. Lowry, "System handbook: advanced communications technology satellite,” NASA TM-101490. 